\title{
IV - Aspectos Específicos da Administração Internacional de Recursos Humanos
}

Vimos, no capitulo anterior, que a transferência de ambiente da administração - do habitat nacional para 0 internacional - afeta, em maior ou menor escala, praticamente todas as suas especialidades.

Vimos, outrossim, que, de todas essas especialidades, a mais afetada é a administração de recursos humanos pelo fato simples e lógico de que ela lida com o único elemento vivo das organizações - o ser humano - ao passo aue todas as demais especialidades lidam com coisas inanimadas ou abstratas, tais como, dinheiro, material, equipamento, estrutura, organização e métodos, chefia e liderança etc. (25).

Dentro do capítulo da administração de recursos humanos ocorre, mutâtis mutandis, fato ou fenômeno semelhante.

O transplante, por exemplo, da classificação de cargos, propriamente dita, do meio nacional para o internacional poucas alterações produz, à semelhança do que ocorre com o mesmo transplante da esfera nacional para a municipal.

Outros capítulos da administração de recursos humanos são, todavia, seriamente afetados pela sua transferência do ambiente nacional para o internacional.

Alguns deles são, a título de ilustração, os referentes ao recrutamento e seleção, ao treinamento, à remuneração, à ética administrativa e à chefia e liderança, para dar apenas os exemplos que nos parecem mais marcantes.

Analisá-los-emos aqui, sucintamente, um por um, pondo em realce as principais diferenciações por que eles passam.

(25) O fato de algumas organizações primitivas ou especializadas usarem animais em suas atividades năo invalida, obviamente, a observação acima, que repte a de página 24.

R. Serv. públ., Brasília, 109 (4) out./dez. 1974 


\section{a) Recrutamento e Seleção}

Os problemas de recrutamento de uma pequena ou média municipalidade de qualquer país afiguram-se pouco significativos e, em alguns casos, até mesmo quase risíveis, pela simplicidade e singeleza, quando comparados, por exemplo, com os da Organização das Nações Unidas.

No primeiro caso, basta à municipalidade anunciar com algum atrativo, no jornal local, se houver, ou, caso contrário, afixar o aviso de vacância do cargo a ser preenchido à entrada do próprio edifício, e o problema de recrutamento estará praticamente resolvido.

No caso das Nações Unidas, organização internacional atualmente com 138 Estados-membros espalhados pelo mundo (além de estar ela própria, como se viu, dispersa por dois continentes) e com cinco idiomas oficiais (inglês, francês, espanhol, russo e chinês), o aviso de vacância deve, para começo de conversa, ser detalhadamente especificado em todos os seus aspectos importantes (qualificações, remuneração, local de trabalho etc.) em cinco línguas diferentes e ser praticamente distribuído por toda a superficie terrestre, para conhecimento dos interessados em todos os Estados-membros, tendo em vista a exigência da justa distribuição geográfica existente na Organização Mundial para o preenchimento dos cargos técnicos dos chamados headquarters, ou seja, a sede de cada uma das organizações-membros.

E evidente que a comparação é, praticamente, entre dois extremos, ou seja, uma pequena ou média municipalidade, de um lado, e, de outro, uma crganização internacional que aspira à universalidade e que, a rigor, já está em vias de atingi-la plenamente (26).

De permeio, existem, porém, os organismos internacionais de âmbito regional - tais como, para dar uns poucos exemplos abrangendo o mundo ocićntal, o mundo socialista e o chamado terceiro mundo, o Mercado Comum Europeu (MCE), o Conselho de Ajuda Econômica Mútua (COMECON), a Organização dos Estados Americanos (OEA) e a Organização da Unidade Africana (OUA) - cujos problemas são, em escala reduzida, os mesmos da ONU, a saber: distância geográfica, variedade de idiomas e multiplicidade de naçöes envolvidas no processo de recrutamento.

Especificamente e em outras palavras, abstraindo-nos dos demais aspectos do problema, o campo de recrutamento de uma administração municipal acha-se, não raro, confinado a uma cidade ou a um conjunto de localida-

(26) Até 1972, as Nações Unidas compreendiam praticamente todo o mundo independente, com exceção da República Popular da China, as 2 Alemanhas, as 2 Corélas e os 2 Vietnams. Com o ingresso da China e das 2 Alemanhas, pouquíssimo falta às Nações Unidas para concretizar plenamente o seu ideal de univer-
salidade.

R. Serv. públ., Brasília, 109 (4) out./dez. 1974 
des vizinhas. O de uma administração nacional está, como regra, dentro do próprio país em que ela se situa; e, com exceção de uns quatro ou cinco, de proporções, por assim dizer, continentais - como a URSS, os Estados Unidos, a República Popular da China, o Canadá ou o Brasil, - a maioria dos países existentes são de dimensões médias ou pequenas e caracterizados, ademais, em geral, por uma certa unidade de idioma, de costumes, de cultura etc., o que, obviamente, facilita muito a tarefa do recrutamento. O campo de recrutamento de um organismo internacional ou de uma empresa multinacional é, com freqüência, um conjunto de países diferentes pela língua, história, cultura etc. E, no caso das Nações Unidas, esse campo é, praticamente, a própria terra em toda a sua extensão e com todas as suas diversidades geográficas, históricas, etnológicas, culturais etc.

Cumpre acrescentar que, além dos funcionários assim recrutados internacionalmente, que são, como regra, os dirigentes ou os profissionais de nivel universitário, contam ainda os organismos internacionais $\theta$ as empresas multinacionais com funcionários, geralmente da categoria dos chamados serviços gerais, recrutados localmente, mais ou menos nas mesmas bases e condições dos nacionais dos paises em que se situam aqueles organismos e empresas.

E, para complicar ainda mais a cena, em algumas dessas organizações internacionais, como, por exemplo, as Nações Unidas, conforme veremos no próximo capítulo, já se desenvolve uma terceira categoria de servidores, chamados semilocais, porque recrutados internacionalmente para funções tipicamente locais, à vista de sua escassez ou mesmo falta no mercado de trabalho do país que abriga a organização internacional, como é o caso, para dar um só exemplo, dos taquígrafos bi-ou-multilingües.

Isso é suficiente, cremos, para oferecer uma idéia dos tremendos problemas com que se defronta $\circ$ recrutamento na administração internacional, nada mais nos parecendo necessário acrescentar a respeito neste trabalho, que v'sa, tão só, a proporcionar ao leitor interessado uma visão panorâmica ou à vol-d'oiseau desse novo e promissor ramo da administração, de que nos ocupamos aqui e que é a gerência ou gestão de recursos humanos a nível internacional.

No que concerne à seleção propriamente dita, os problemas com que se defrontam os organismos internacionais e as empresas multinacionais não sf revelam menores.

Como no caso do recrutamento, há igualmente, sempre presentes, a aistância geográfica, a barreira lingüística e a multiplicidade de nações as mais diversas envolvidas no processo.

Isso obriga a seleção a adotar métodos e técnicas de menor uso nas administrações nacionais e, sobretudo, municipais. 
Um concurso ou prova competitiva, do tipo tão merecidamente em voga nas administrações nacionais e municipais mais evoluídas, seria totalmente impraticável, salvo casos excepcionais, na seleção de funcionários recrutados internacionalmente, pelos altíssimos custos que envolveria e por muitas outras e óbvias razões.

Por outro lado, o bom êxito em missões internacionais exige, além das qualificações técnicas indispensáveis, um conjunto de fatores especiais, que são enfatizados pelos especialistas na matéria e têm, necessariamente, de ser objeto de acurada investigação, por processos seletivos os mais seguros e dignos de confiança.

Franklin R. Root e David A. Heenan, por exemplo, baseando-se na vivência de experimentados dirigentes de organizações e empresas internacionais, de modo geral, mencionam, como alguns desses fatores:

a) Sensibilidade por ambiente estrangeiro, ou seja, em sintese, sentimentos de simpatia e solidariedade humana, aliados a decidido desejo de aprender o idioma nativo e compreender a cultura local, em seu sentido mais amplo.

b) Flexibilidade, ou seja, facilidade de adaptação a novos ambientes, sem maiores problemas.

c) Motivação para servir no exterior, sem o que os demais requisitos serão inócuos.

d) Adequado suporte familiar, pois está comprovado que técnicos altamente qualificados em tudo o mais têm malogrado em suas missőes internacionais pelos conflitos domésticos resultantes da inadaptação das respectivas famílias ao ambiente alienígena (27).

Ernest Dale, mais metódico, enumera sete fatores, dos quais quatro parecem ser básicos e três adicionais, a saber :

1. Racional motivação para servir no exterior.

2. Fluência em idiomas e conhecimento do meio ambiente.

3. Ausência de preconceitos no que concerne a raças, religiöes ou culturas.

(27) "Staffing the Overseas Unit" in Handbook of Modern Personnel Administration, Joseph J. Famularo, Editor-in-Chief, New York, McGraw-Hill Book Company, 1972, Cap. 56, p. 8.

R. Serv. públ., Brasília, 109 (4) out./dez. 1974 
4. Ausência de excessivo apego ao país natal.

5. Flexibilidade, ou seja, facilidade de mudança de hábitos alimentares, habitacionais e sociais, de modo geral.

6. Inventividade, ou seja, capacidade de criar derivativos para entreterse em situações solitárias ou de pouco convívio humano (como pode ocorrer, principalmente no inicio de uma missão internacional).

7. Laços familiares ou emocionais, ou seja, em outras palavras, o suporte familiar a que se referem Root e Heenan (28).

Robert C. Zuehlke - depois de afirmar que o sucesso em missões internacionais depende basicamente de quatro fatores, a saber, saúde, facilidade de idiomas, qualificações técnicas e traços pessoais - enumera, entre estes :

1. Facilidade de adaptação.

2. Espírito social.

3. Auto-suficiência.

E, como processos mais indicados para a boa seleção de funcionários internacionais, menciona Robert Zuehlke:

a) o exame físico;

b) a verificação de curriculum e referências;

c) a entrevista pessoal em profundidade (depth interview);

d) testes psicológicos;

e) a entrevista psiquiátrica.

"Ademais", - acrescenta Zuehlke - "ao considerar candidato para missâo internacional, a esposa e outros membros de sua familia imediata devem SEr também objetos de avaliação" (29).

(28) Ernest Dale, Management: Theory and Practice, New York, McGraw-Hill Book Company, 1969, Part - 4 "Management of Foreign Operations", p. 653.

(29) "Hiring Employees for Foreign Assignments" in International Handbook of Management, edited by Karl E. Ettinger, New York, McGraw-Hill Book Company, 1965. pp. 191-195. 
Como se vê, a seleção para cargos ou funções típicas da administração internacional difere consideravelmente, tanto em conteúdo como em processos, da seleção para cargos ou funções comuns das administrações nacionais.

Concluindo este tópico, cremos poder afirmar que o recrutamento e a seleção internacionais apresentam características próprias, que os distinguem nitidamente do recrutamento e da seleção comuns às administrações nacionais e municipais.

E as dificuldades existentes são de tal ordem que um eminente autor inglês chega a propor o estabelecimento de um Serviço de Pessoal Mundial (World Personnel Service) para atender às demandas em recursos humanos internacionais qualificados das organizações e empresas internacionais, em geral :

"Esse serviço de pessoal deveria ser o mecanismo mais simples possivel para pôr em contato pessoas capazes e desejosas de servir no exterior com governos e companhias que as quisessem empregar. Por outro lado, estudantes e treinandos à busca de oportunidades para aprender seriam postos em contato com aqueles que estivessem oferecendo tais oportunidades de aprendizagem" (30).

\section{b) Treinamento}

O treinamento ou desenvolvimento de recursos humanos é outro capitulo da administração de pessoal que assume nova feição no ambiente internacional.

Isso como resultado dos mesmos fatores que influenciam em sentido semelhante a seleção, a saber: a barreira lingüística, a necessidade de adapt3ção ao meio ambiente, não raro completamente diverso daquele em que vive o servidor, e a necessidade de compreensão de outras culturas e outros padrões de conduta, sem falar nas qualificações profissionais, que muitas vezes têm necessidade de ser aprimoradas, já que seleção e treinamento, diversamente do que muita gente pensa, são processos complementares e não competitivos ou exclusivos, um em relação ao outro.

Quando um organismo internacional ou uma empresa multinacional admite um profissional para enviá-lo a seu serviço ao exterior, já se espera, na imensa maioria dos casos, que esse profissional possua o instrumental lingüistico riecessário ao bom desempenho de sua missăo, o que é, geralmente, verificađó no processo seletivo. Em uns poucos casos, porém, como observa, ainda, Robert C. Zuehlke, se as qualidades profissionais $\theta$ os traços pessoais de um

(30) Stanley Hyman, Management and World Development, London, Sir Isaac Pitman and Sons, 1967, pp. 107-108.

R. Serv. públ., Brasilia, 109 (4) out./dez. 1974 
candidato se mostram excepcionais ou fora do comum, vale a pena admiti-lo, mesmo que o seu conhecimento lingüistico seja deficiente, e submetê-lo a intensivo e bem planejado programa de treinamento nesse particular, como se faz, por exemplo, com astros de cinema (31).

Parte importante e indispensável do treinamento é, todavia, a que se destina a suprir as deficiências ou mesmo carência do candidato no que concerne ao conhecimento do país em que vai servir e seu meio ambiente tanto fisico como social, com o objetivo de facilitar a sua adaptação e a de sua família ao seu novo local de trabalho. Aqui, mais uma vez, se evidencia a imfortância extraordinária do suporte familiar para o bom êxito da missão do funcionário internacional, pois, como observa Ernest Dale, "mesmo às esposas é atribuída participação em alguns programas de preparação" (32).

Até agora, nesta visão panorâmica do problema, o temos encarado somiente do prisma do envio de técnicos de um país a outro para aí desempenharem as suas funções internacionais. Mas, há também o reverso da medalha, ou seja, o treinamento de nacionais do próprio país que hospeda a empresa multinacional ou o organismo internacional, para nele exercerem funções de responsabilidade dentro da organização. Isso, porém, é mais comum nas empresas multinacionais, porque grande parte dos organismos internacionais, inclusive e sobretudo a ONU e sua família de organizações, preferem, salvo casus excepcionais, não ter nacionais de um país trabalhando em sua própria pátria em funções ditas "profissionais" (de nivel universitário) ou diretivas.

Encarando o problema sob outro prisma e quase exclusivamente no interesse das empresas multinacionais, escrevem Root e Heenan :

"Programas intensivos de desenvolvimento de recursos humanos se mostram particularmente necessários pelas seguintes características inerentes à carreira internacional :

1. Supercentralização das decisões operacionais pela matriz da empresa.

2. Descompasso informacional entre a subsidiária do exterior e a matriz.

3. Exigência no sentido de que gerentes amadurecidos no exterior retornem, em alguma oportunidade, a atividades regionais ou na matriz para funções diretivas.

(31) Op. cit., p. 194.

(32) Op. cit., p. 653. 
4. Tendência para acelerado desenvolvimento de nacionais locais, não só nas organizações subsidiárias, mas também nas regionais e na matriz (33).

Qualquer que seja a modalidade ou tipo de treinamento, uma coisa é, contudo, certa, conforme assinala Ernest Dale :

"Realizando substancial investimento no pessoal que enviam ao exterior, as companhias levam o treinamento de seus candidatos tão a sério como a sua seleção" (34).

Isso é também verdadeiro em relação aos organismos internacionais e, nas empresas multinacionais, também em relação aos técnicos locais treinados para assumirem nelas postos de responsabilidade, conforme se viu.

\section{c) Remuneração}

Se, no terreno do recrutamento, seleção e treinamento, a multiplicidade de línguas e a diversidade de meios ambientes constituem um obstâculo e um desafio à argúcia do administrador de recursos humanos na esfera internacional, no campo da remuneração nos deparamos, paralelamente, com :

a) a multiplicidade de moedas;

b) a diversidade dos níveis de custo de vida.

Esses são apenas dois fatores, por assim dizer, extrínsecos, que complicam, ainda mais, o problema da remuneração dos funcionários internacionais, sejam das empresas multinacionais, sejam dos organismos internacionais.

Vendo o problema do prisma do profissional norte-americano que se expatria para servir alguma empresa internacional no estrangeiro, Alfred $\mathrm{J}$. Figliola escreve :

"A remuneração do expatriado norte-americano destina-se a :

1) conferir-lhe uma renda líquida pelo menos igual à do indivíduo que desempenha na terra natal trabalho semelhante e do mesmo status financeiro;

2) proporcionar-lhe um incentivo ou prêmio financeiro razoável, capaz de induzi-lo a trabalhar e residir no exterior. Isso compreende o pagamento de um salário básico, um prêmio de serviço estrangeiro e adicionais de moradia

(33) Op. cit., Cap. 56, p. 9

(34) Op. cit., p. 653.

R. Serv. públ., Brasília, 109 (4) out./dez. 1974 
e de condições de vida. Quando não combinada com o prêmio de serviço estrangeiro, uma gratificação separada por motivo de hardship ou "choque cultural" é também paga. Em acréscimo, protege-se convenientemente o expatriado contra taxações excessivas de imposto de renda e, sempre que adequado, concede-se-lhe um auxílio para custos de educação. Na essência, essas considerações representam os diversos fatores que são normalmente levados em conta para cada país ou local de serviço. Neles está implícito o reconhecimento das diferenças de interesse existentes por lugares diversos em razão de condições climáticas ou outras de natureza permanente. E, por meio deles, procura-se, outrossim, tornar mais fáceis as transferências de pessoal, eliminando ou minimizando o efeito sobre os funcionários das variações de convenção prevalecentes em distintas áreas ou locais de serviço" (35).

E Alfred Figliola - que é um dos Vice-Presidentes do First National City Bank de Nova lorque, no setor de atividades internacionais, e ali responsável pelo desenvolvimento e pesquisa de sistemas de salário - enumera especificamente, analisando uma por uma, as diversas vantagens de natureza financeira ou semelhante que se atribuem, como regra, aos funcionários internacionais das empresas multinacionais, a saber:

- Salário básico (base pay) .

- Prêmio de serviço estrangeiro (foreign service premium).

- Adicional de custo de vida (differential cost of living allowance).

- Gratificação de subsistência por separação (separate maintenance allowance).

- Adicional de moradia (housing allowance), que pode assumir também a forma de fornecimento de dependências não mobiliadas (unfurnished quarters), de ocupação de moradias possuídas ou alugadas pela companhia (company leased or ownership of homes) ou de aquisição de casas (purchase of homes) com o auxílio da companhia.

- Auxílio-educação (education allowance) .

- Licença para visitar o país natal (home leave), com as vantagens a ela ligadas, a saber: bilhetes de viagem e despesas correlatas (home

leave travel allowances) e gastos de subsistência em trânsito (living expenses in transit).

- Reembolso por imposto de renda (reimbursement of income taxes) pago indevida ou excessivamente (36).

(35) "Compensation of Overseas Personnel" in Handbook of Modern Personnel Administration, Editor-in-Chief, Joseph J. Famularo, New York, McGraw-Hill Book Company, 1972, Cap. 57, pp. 2-16.

(36) Idem, ibidem, Cap. 57, pp. 2-16.

R. Serv. públ., Brasília, 109 (4) out./dez. 1974 
Mutatis mutandis, não só no que concerne à terminologia empregada, mas também à diferença de características próprias de cada tipo de organização, possui a ONU e sua família de organizações um sistema de remuneração semelhante, que compreende, entre outras, as seguintes vantagens, além do salário básico:

- Salário-família (dependency allowance). - Pago em relação a três tipos de dependentes: 1) mulher ou marido dependente; 2) filho ou filha dependente; e 3 ) dependente secundário, como tal entendendo-se progenitor, irmão ou irmã dependente. O conceito de dependência, rigorosamente averiguado para qualquer dos casos enumerados, é condição sine qua non para o pagamento da vantagem.

- Auxílio-educação e viagem correspondente (education grant and related travel). - Pago em relação a cada filho de funcionário internacional que sirva fora de seu país natal, desde que estude, em regime de tempo integral, em uma escola, universidade ou instituição educacional similar. O auxílio corresponde basicamente a $75 \%$ das despesas efetuadas, sujeito a um limite máximo, e a viagem é concedida anualmente.

- Ajuda de custo (installation allowance). - Paga a todo funcionário que, em virtude de nomeação ou transferência, é obrigado a mudar de local de trabalho. A ajuda de custo para cada membro da família corresponde à metade do que é atribuível ao funcionário.

- Gratificação de exercício ou local (assignment allowance). - Paga a funcionário designado para servir fora de seu país natal por um período de, pelo menos, um ano e que não transporte a sua mudança por conta da organização. Essa vantagem não pode ser paga por período superior a cinco anos.

- Gratificação por idioma (language allowance). - Paga a funcionário que demonstre conhecimento adequado de mais de um dos idiomas oficiais da organização.

- Indenização por dispensa (termination indemnity). - Paga a funcionário que é dispensado por iniciativa da organização. Não é devida a quem deixa a organização voluntariamente, se aposenta ou é dispensado por motivos disciplinares.

- Indenização de repatriamento (repatriation grant). - Paga a funcionário que a organização é obrigada a repatriar após o término dos serviços. Não é devida a quem seja dispensado por motivos disciplinares. Destina-se a assistir o funcionário nas despesas de reinstalação em seu país natal, após um mínimo de tempo de serviço no exterior. 
- Auxílio Funeral (grant on death). - Pago aos dependentes de funcionário que morre em serviço após um mínimo de tempo na organização.

Menção à parte, pela sua peculiaridade, merece o post-adjustment, de que ainda falaremos adiante e é a parte da remuneração do funcionário das Nações Unidas destinadas a cobrir as diferenças de custo de vida existentes entre os diversos países em que elas operam, os quais são, praticamente, todos do mundo. A finalidade do post-adjustment - dentro do mais rigoroso espírito do sistema comum - é fazer com que os funcionários das mesmas categorias, servindo em localidade de custo de vida diferente, tenham o mesmo poder aquisitivo, ainda que ganhando diversamente ou, melhor, por isso mesmo.

Para fins de estabelecimento de adequados quantitativos de post-adjustment, os países ou localidades em que as Nações Unidas têm serviços são periodicamente classificados em um certo número de categorias, de acordo com os índices de custo de vida apurados pela ONU e pela OIT, com a colaboração de todas as demais organizações.

Eis, em linhas gerais e em resumo muito breve, como funciona e em que consiste, no que se refere tão somente às principais vantagens de ordem salarial ou financeira, o sistema comum de salários, vantagens e outras condições de serviço das Nações Unidas, ao qual voltaremos a nos referir no capítulo $\mathrm{V}$, quando tratarmos especificamente da ONU e a administração internacional de recursos humanos (37).

\section{d) Ética Administrativa}

A ética administrativa é outro capítulo da administração de recursos humanos que sofre considerável transformação quando transportado para o ambiente internacional.

A vida particular de um servidor nacional, por exemplo, é, salvo casos excepcionais, assunto privativo dele. E há casos concretos de excelentes servidores no interior das repartições, mas que fora, na rua ou no lar, são péssimos cidadãos e piores chefes de família. A repartição a que ele pertence nada tem a ver, bbviamente, com esses aspectos particulares de sua vida, desde que eles não interfiram em sua atividade profissional ou não se constituam em notórios casos de escândalo público.

$\mathrm{Na}$ administração internacional - assim como também na diplomática da maioria dos países - as coisas não são e não podem ser assim.

(37) A. Fonseca Pimentel, O Sistema Comum de Salários, Vantagens e Outras Condiçōes de Serviço das Nações Unidas, DASP, Centro de Documentação e Informática, 1970. 
O funcionário nacional em seu próprio país é uma classe de empregado ou trabalhador da nação, como o comerciário, o industriário, o bancário, com uns poucos privilégios ou restrições a mais. No fundo, porém, pode-se dizer que é um servidor como os outros.

O mesmo não ocorre com o funcionário internacional, principalmente dos organismos internacionais propriamente ditos, e os diplomatas de modo geral.

Estes são encarados na terra em que servem como a personificação de seu próprio país natal, que representam, não só diplomaticamente, mas também física, cultural e moralmente perante os cidadãos do país hospedeiro.

E aqueles - os funcionários internacionais - são, por sua vez, vistos pela comunidade local, além de como técnicos, também como representantes físicos, culturais e morais dos organismos a que pertencem.

Ambos - diplomatas e funcionários internacionais - formam, pois, no seio da sociedade em que se inserem, classes distintas e, por assim dizer, de elite, cuja conduta é permanentemente acompanhada e observada pela comunidade, que deles espera atitudes de respeito para com seus usos e costumes, seus hábitos, suas crenças, suas tradições, seus padrões culturais etc.

Daí que a ética administrativa de um diplomata há de ser bem mais estrita e rigorosa do que a de um funcionário comum em seu próprio país natal. $\mathrm{E}$ a do funcionário internacional - que tantos pontos de contato apresenta com o diplomata - há de ser pelo menos do mesmo nível de rigor deste, senão mesmo superior, pois o organismo internacional, além de não constituir nação soberana que trate com o país hospedeiro de igual para igual, representa, por outro lado, se bem que apenas técnica e administrativamente, um conglomerado maior ou menor de nações.

Como conseqüência, as exigências de ordem ética feitas ao funcionário internacional - pelo menos dos organismos internacionais propriamente ditos, conforme já se mencionou - revelam-se muito rigorosas.

As próprias Staff Regulations - principal documento legal sobre pessoal — das Nações Unidas se ocupam do assunto, dispondo :

"301.014 Os funcionários da Organização comportar-se-ão em todas as oportunidades de maneira adequada a seu status de servidores civis internacionais. Não participarão de qualquer atividade que seja incompatível com o conveniente exercício de seus deveres com a Organização. Evitarão qualquer ação e, em particular, qualquer espécie de pronunciamento público que possa adversamente refletir em seu status. Ainda que não se espere que renunciem aos seus sentimentos nacionais ou às suas convicções políticas e religiosas, deverão eles ter sempre em vista a reserva e o tacto com que deverão agir em qualquer tempo por motivo de seu status internacional.

R. Serv. públ., Brasília, 109 (4) out./dez. 1974 
301.015 Os funcionários da Organização observarão a mais completa discrição no que concerne a todos os assuntos oficiais. Não comunicarão a qualquer pessoa nenhuma informação que conheçam em razão de sua posição oficial e que não tenha sido tornada pública, exceto no exercício de seus deveres ou com autorização do Secretário-Geral. Nem usarão eles, em qualquer oportunidade, tais informações para proveito pessoal. Essas obrigações não cessam com o desligamento da Organização.

301.016 Nenhum funcionário da Organização aceitará qualquer honra, condecoração, favor, presente ou remuneração de qualquer governo, salvo por serviço de guerra; não aceitará, outrossim, qualquer honra, condecoração, favor, presente ou remuneração de fontes externas à Organização, sem primeiro obter a aprovação do Secretário-Geral. Tal aprovação somente será concedida em casos excepcionais e quando a aceitação não for incompatível com os termos das Disposições 301.012 e 301.0121 e com o status da pessoa como servidor civil internacional. " (38).

\section{E mais :}

“301.017 Qualquer funcionário da Organização que se candidatar a função pública de caráter político se exonerará de seu cargo na Organização."

Em conseqüência, não pode o funcionário internacional fazer nada, mesmo em sua vida privada, que possa trazer descrédito para a organização a que pertence.

O assunto é levado tão seriamente que já foi objeto de um estudo-inves. tigação no seio das Nações Unidas, do qual resultou importante documento a respeito: Report on Standards of Conduct in the International Service, United Nations, 1954 (COORD/CIVIL SERVICE).

Nesse documento, lê-se textualmente :

"A fim de que a sua (do funcionário internacional) vida privada não traga descrédito para a Organização, deve ele seguir alto padrão de conduta pessoal, mais complexo a vários respeitos do que é exigido dos servidores civis nacionais. Deve o funcionário internacional ter sempre em mente que a sua conduta, esteja ou não ligada ao desempenho de funções oficiais, há de ser tal que não fira quaisquer interesses claros da Organização a que ele serve, não a coloque em descrédito ou ofenda

(38) As disposições citadas determinam que o servidor internacional está sob a autoridade do Secretário Geral, sujeito às suas ordens e com todo o seu tempo à disposição dele. 
a comunidade em que ele vive. Não somente deve o funcionário intercional ser, ele próprio, cuidadoso e discreto, mas, outrossim, deve transmitir aos membros de sua família a necessidade de manterem, igualmente, esse alto padrão de conduta."

E um folheto de treinamento destinado a consultores internacionais repete :

"O consultor deve ter sempre a consciência do fato de que aos olhos das autoridades locais e da comunidade ele representa a sua Organização e as Nações Unidas e que o seu comportamento pessoal se reflete imediatamente no prestígio das organizações internacionais." (39).

Como resultado, não parece exagero dizer que os padrões de conduta ética dos servidores internacionais dos organismos internacionais afiguram-se mais elevados do que os da esmagadora maioria das administrações nacionais, inclusive, tal como expostos de forma rigorôsa, em um dos livros clássicos sobre a matéria (Paul H. Douglas, Ethics in Government, Cambridge-Massachusetts, Harvard University Press, 1952).

No que concerne aos privilégios e imunidades de que gozam os funcionários internacionais, são as Staff Regulations muito cuidadosas ao estabelecer as condições de seu uso :

“301.018 Os funcionários da Organização gozam dos privilégios e imunidades a que se refere o artigo VIII da Constituição e a Convenção sobre Privilégios e Imunidades das Agências Especializadas, nos casos em que essa Convenção tenha sido ratificada pelos governos interessados. Esses privilégios e imunidades são concedidos no interesse da Organização. Não devem eles, porém, servir de motivo de excusa, por parte dos funcionários que gozam deles, para deixarem de cumprir suas obrigações particulares ou as leis e regulamentos policiais. Em qualquer caso em que esses privilégios e imunidades sejam postos em questão, deve o funcionário informar imediatamente o Secretário-Geral, a quem, única e exclusivamente, cabe decidir sobre a renúncia ou não a ditos privilégios e imunidades."

\section{e) Liderança e Chefia}

O problema da chefia e liderança, um dos mais cruciais em qualquer tipo de administração, conforme o demonstrou magistralmente Estelita Campos em obra que é hoje um dos clássicos de nossa literatura administrativa (40),

(39) United Nations, Briefing of International Consultants, New York, United Nations, 1964.

(40) A Chefia, sua técnica, seus problemas, 6. ${ }^{a}$ ed., Fundação Getúlio Vargas, 1973.

R. Serv. públ., Brasília, 109 (4) out./dez. 1974 
assume complexidade excepcional na administração internacional, como é fácil de perceber.

Em primeiro lugar, surge aqui também a barreira lingüística. Liderança e chefia adequadas exigem comunicações claras e precisas. $O$ dirigente internacional, entretanto, é obrigado, não raro, a comandar e liderar, oralmente e por escrito, em um idioma que não é o seu e, muitas vezes, em mais de um idioma. O seu domínio de tais idiomas deve, pois, ser perfeito, mais do que é exigido de um simples profissional subordinado; do contrário, faltar-lhe-á um dos instrumentos básicos da chefia e da liderança, que é a comunicação.

Ademais, o dirigente internacional comanda, com freqüência, equipes cosmopolitas, ou seja, compostas de elementos de nacionalidades e raças as mais diversas, cáda um com as suas crenças, religião, superstições e a sua escala de valores, não raro incompatíveis umas com as outras.

Isso, como é óbvio, complica, sobremaneira, o problema das relações humanas do grupo, exigindo do dirigente qualidades excepcionais de tato, diplomacia, paciência e criatividade, para evitar choques e conflitos sempre pendentes, como uma espada de Dâmocles sobre o moral da organização e altamente prejudiciais para o esprit de corps da equipe.

A isso acresce que, às vezes, esse comando, já extremamente difícil em si mesmo, complica-se, ainda mais, por ter que se efetuar à distância e, às vezes, à distância de milhares de quilômetros.

\section{Daí haver um autor escrito com razão :}

“Assim, uma pessoa pode adquirir competência como administrador internacional de pessoal, o que é mais amplo do que a competência na administração de pessoal de um específico país estrangeiro e distinto da competência em administração de pessoal de seu próprio país natal." (41).

E o que afirma também G. A. Costanzo com toda a sua responsabilidade pelos negócios internacionais do First National City Bank, de Nova lorque :

"O homem que tem sido um dirigente eficaz em operações nacionais nem sempre é igualmente eficaz num contexto internacional. A experiência sugere que os homens de negócios internacionais devem possuir certas qualidades que não são essenciais para o sucesso nos negócios dentro do próprio país, embora possam fazer a diferença entre o sucesso e o fracasso nas operações internacionais."

(41) John Fayerweather, Op. cit. ,p. 2.

R. Serv. públ., Brasília, 109 (4) out./dez. 1974 
$E$, entre essas qualidades, menciona o autor : a disposição para viver e trabalhar fora de seu habitat natural; elevada flexibilidade ou capacidade de adaptação a situações novas e a culturas estrangeiras; mente perscrutadora e analítica, com alta capacidade de decisão mesmo em face de insuficiência de dados; empatia no modo de encarar novas pessoas e novas situações; atitude diplomática no trato com pessoas de todos os níveis; autêntico interesse em laços mais estreitos entre as nações e sentido de envolvimento na tarefa do desenvolvimento econômico, na melhoria dos padrões de vida em todo o mundo.

A essas qualidades ou características pessoais adiciona o autor conhecimentos e habilitações tais como: conhecimento do idioma do lugar em que o dirigente vai atuar; posse de instrumentos profissionais aperfeiçoados e adequados, no sentido mais amplo da expressão; familiaridade com o que está acontecendo no mundo; conhecimento básico de economia internacional (42).

\section{f) Outros Aspectos}

Vários outros capítulos da administração de recursos humanos são, obviamente, afetados de maneira sensível pela dimensão internacional ou multinacional que a administração vem recentemente assumindo.

Infelizmente, não nos será possível tratar de todos eles nesta obra, que, conforme se esclareceu, é apenas uma introdução ao estudo da nova disciplina que emerge no vasto e prolífico campo da administração e uma como que chamada de atenção para ela no que concerne aos possíveis e numerosos interessados em seu estudo e aplicação prática.

Não podemos, todavia, deixar de mencionar, ainda que só de passagem, tais capítulos, a saber : o da movimentação de pessoal ou turnover; o do regime disciplinar, o dos recursos (appeals), o do regime jurídico e, last but not least, o da formação de dirigentes especificamente para a administração internacional ou multinacional, a que se acaba de fazer menção, de passagem.

(42) "O Dirigente Multinacional". Cap. 18 da obra de Peter Drucker e outros Forma. ção de Dirigentes, Rio, Editora Expressão e Cultura, 2." ed., 1971, pp. 325-26.

R. Serv. públ., Brasília, 109 (4) out./dez. 1974 